\title{
The effect of priming injection of different doses of remifentanil on injection pain of microemulsion propofol premixed with lidocaine
}

\author{
Cheol Won Jeong, Seong Heon Lee, Jin Ju, Seong Wook Jeong, and Hyung Gon Lee \\ Department of Anesthesiology and Pain Medicine, Chonnam National University Mediacal School, Gwangju, Korea
}

Background: The injection pain of microemulsion propofol is frequent and difficult to prevent. This study examined the prevention of pain during microemulsion propofol injection by pretreatment with different doses of remifentanil or saline, and premixing of lidocaine.

Methods: One hundred sixty ASA physical status 1-2 adult patients scheduled for elective surgery were enrolled into one of four groups ( $\mathrm{n}=40$, in each). The patients received saline (group LS), remifentanil $0.3 \mu \mathrm{g} / \mathrm{kg}$ (group LR 0.3 ), remifentanil $0.5 \mu \mathrm{g} / \mathrm{kg}$ (group LR 0.5), or remifentanil $1.0 \mu \mathrm{g} / \mathrm{kg}$ (group LR 1.0), and after 90 seconds received an injection of $2 \mathrm{mg} / \mathrm{kg}$ microemulsion propofol premixed with lidocaine $40 \mathrm{mg}$. Pain was assessed on a four-point scale during microemulsion propofol injection.

Results: The incidence of microemulsion propofol-induced pain was significantly lower in the LR 0.3, LR 0.5 and LR 1.0 groups than in the LS group (37.5\%, $12.5 \%$ and $10 \%$ vs $65 \%$, respectively). The LR 0.5 and LR 1.0 groups showed significantly less frequent and intense pain than the LR 0.3 group. However, both incidence and severity of pain were not different between LR 0.5 and LR 1.0 groups.

Conclusions: The combination of remifentanil and lidocaine is effective in alleviating pain associated with a microemulsion propofol injection compared with just lidocaine. Remifentanil $0.5 \mu \mathrm{g} / \mathrm{kg}$ had a similar analgesic effect compared to the $1.0 \mu \mathrm{g} / \mathrm{kg}$ dose. (Korean J Anesthesiol 2011; 60: 78-82)

Key Words: Lidocaine, Microemulsion propofol, Pain, Remifentanil.

Received: June 30, 2010. Revised: 1st, July 15, 2010; 2nd, August 9, 2010. Accepted: August 10, 2010.

Corresponding author: Hyung Gon Lee, M.D., Ph.D., Department of Anesthesiology and Pain Medicine, Chonnam National University Mediacal School, Hak-dong, Dong-gu, Gwangju 501-757, Korea. Tel: 82-62-220-6893, Fax: 82-62-232-6294, E-mail: leehg@chonnam.ac.kr

(c) This is an open-access article distributed under the terms of the Creative Commons Attribution Non-Commercial License (http:// creativecommons.org/licenses/by-nc/3.0/), which permits unrestricted non-commercial use, distribution, and reproduction in any medium, provided the original work is properly cited. 


\section{Introduction}

Propofol (2,6-diisopropylphenol), an intravenous hypnotic, has gained popularity as an agent for both induction and maintenance of anesthesia due to its rapid onset, short duration of action, and minimal side effects. The currently used longchain triglyceride (LCT) emulsion propofol formulations have several drawbacks including inherent emulsion instability, need for antimicrobial agents, hyperlipidemia, pancreatitis, and pain on injection [1-4]. This has led to the development of improved formulations for this compound [5].

A lipid-free microemulsion propofol (Aquafol ${ }^{\circledR}$; Daewon Pharmaceutical, Seoul, Korea) was developed to eliminate lipid solvent-related adverse events of LCT emulsion propofol. Microemulsion propofol demonstrated similar pharmacokinetics and pharmacodynamics to lipid emulsion propofol [6]. It has also been reported that microemuslion propofol is as effective and safe as lipid emulsion propofol [7]. However, microemulsion propofol produces more frequent and severe pain upon injection than lipid emulsion propofol and the significantly higher incidence and severity of pain on injection with microemulsion propofol is associated with a higher aqueous free propofol concentration $[7,8]$. In one study, $70 \%$ of patients who received microemulsion propofol reported considerable pain on injection [8].

There are a number of studies on the pharmacologic and nonpharmacologic strategies for the prevention of pain on propofol injection. They include premedication [9], cooling or diluting of the propofol solution $[10,11]$ and concomitant therapies using ketamine [12], local anesthetics [13], ondansetron [14], and opioids [15,16]. However, despite various methods to reduce propofol injection pain, none of these have achieved the complete elimination of pain. Previous studies show that multimodal analgesia using different analgesic modalities can reduce the incidence and severity of propofol injection pain [17-19]. Also, a recent study shows that the combination of remifentanil and lidocaine was more effective in reducing the incidence of pain upon the injection of microemulsion propofol than either treatment alone [20].

The aim of the present study was to evaluate the effect of a combination of pretreatment with different doses of remifentanil and premixing of lidocaine on the incidence and severity of microemulsion propofol injection pain in adults undergoing elective surgery.

\section{Materials and Methods}

This study received Institutional Review Board approval, and informed consent was obtained from each patient. A total of 160 patients, aged 20 to 65 years, who were scheduled for elective surgery with general anesthesia and were American Society of Anesthesiologists (ASA) status I and II, were enrolled. Patients who had known allergy to any drugs; had renal, hepatic, or cardiac problems; had asthma, diabetes mellitus, neurologic deficits and psychiatric disorders; required a rapid sequence induction; or had received analgesics or sedatives within the 24 hours previous to enrolment were excluded.

The patients were randomly assigned to one of the four groups according to the dose of remifentanil using an Excel (Microsoft, USA) generated randomization table. The four groups were comparable with respect to patient characteristics (Table 1). No patient was excluded from the analysis due to complications and therefore data for all 160 patients is presented.

The patients received saline (LS group, $n=45$ ), remifentanil $0.3 \mu \mathrm{g} / \mathrm{kg}$ (LR 0.3 group, $\mathrm{n}=45$ ), remifentanil $0.5 \mu \mathrm{g} / \mathrm{kg}$ (LR 0.5 group $\mathrm{n}=45$ ), or remifentanil $1.0 \mu \mathrm{g} / \mathrm{kg}(\mathrm{LR} 1.0$, group $\mathrm{n}=45$ ) over a $30 \mathrm{~s}$ period, and $90 \mathrm{~s}$ later received an injection of $2 \mathrm{mg} /$ $\mathrm{kg}$ microemulsion propofol premixed with lidocaine $40 \mathrm{mg}$ over a $60 \mathrm{~s}$ period. Saline and remifentanil were prepared in a $10 \mathrm{ml}$ unlabeled syringe by individuals who had not participated in the induction of anesthesia. Microemulsion propofol was mixed with $2 \mathrm{ml}$ of $2 \%$ lidocaine. The patients, anesthesia providers and investigators who scored the movements were blinded to the treatment group. All study drugs were prepared before the injection at room temperature.

Before arriving at the operating room, a 20 gauge cannula was inserted in the left cephalic vein of the patient's nondominant hand, and its position was confirmed by the free flow of Hartmann's solution infused by gravity. Standard monitoring, including noninvasive arterial pressure, ECG, pulse oximetry and bispectral index score (BIS) monitoring was applied and assessed continuously. Before induction of anesthesia, all patients were preoxygenated. After remifentanil or saline injection, microemulsion propofol $2 \mathrm{mg} / \mathrm{kg}$ was administered through the rubber port connected to the intravenous cannula without the carrier fluid. The assessment of pain was made continuously from the start of the propofol injection to when

Table 1. Demographic Data of the Patients in This Study

\begin{tabular}{lcccc}
\hline & $\begin{array}{c}\text { LS } \\
(\mathrm{n}=40)\end{array}$ & $\begin{array}{c}\text { LR 0.3 } \\
(\mathrm{n}=40)\end{array}$ & $\begin{array}{c}\text { LR 0.5 } \\
(\mathrm{n}=40)\end{array}$ & $\begin{array}{c}\text { LR 1.0 } \\
(\mathrm{n}=40)\end{array}$ \\
\hline Sex (M/F) & $20 / 20$ & $20 / 20$ & $20 / 20$ & $20 / 20$ \\
Age (yr) & $46(12)$ & $46(10)$ & $49(10)$ & $48(9)$ \\
Weight (kg) & $64.0(11.1)$ & $59.8(8.9)$ & $64.1(10.3)$ & $62.1(10.1)$ \\
Height (cm) & $164.1(8.1)$ & $163.6(7.9)$ & $163.6(8.5)$ & $162.6(6.8)$ \\
\hline
\end{tabular}

Values are shown as mean (SD) or number of patients. There were no significant differences between groups. LS: lidocaine $40 \mathrm{mg}+$ saline $10 \mathrm{ml}$, LR 0.3: lidocaine $40 \mathrm{mg}+$ remifentanil $0.3 \mu \mathrm{g} / \mathrm{kg}$ in 10 $\mathrm{ml}$, LR 0.5: lidocaine $40 \mathrm{mg}+$ remifentanil $0.5 \mu \mathrm{g} / \mathrm{kg}$ in $10 \mathrm{ml}$, LR 1.0: lidocaine $40 \mathrm{mg}+$ remifentanil $1.0 \mu \mathrm{g} / \mathrm{kg}$ in $10 \mathrm{ml}$. 
patients lost their consciousness. The severity of pain was assessed using a four-point scale. Pain manifestation as a verbal response accompanied by facial grimacing or withdrawal of arm was scored as severe; grimacing or withdrawal not accompanied by a verbal response was scored as moderate pain. If severe or moderate pain was not observed, the patient was asked whether they had any discomfort in the arms; if they answered 'yes', this was scored as mild pain; if they answered 'no', this was scored as no pain [21]. After the loss of an eyelash reflex, the patients were intubated after administration of rocuronium $0.8 \mathrm{mg} / \mathrm{kg}$. Anesthesia was then carried on normally.

After the remifentanil or saline injection, BIS score was checked to subjectively assess the level of consciousness to ensure an adequate response to the pain questionnaires. The mean arterial pressure and heart rate were recorded before injecting the study drug (baseline), after the remifentanil injection, and before tracheal intubation. Chest wall rigidity, described as transient chest discomfort, was also recorded during remifentanil injection. Patients were monitored hourly for 24 hours post-surgery by a blinded investigator for adverse effects at the injection site such as pain, edema, wheal and flare response.

Based on previously published data, the incidence of pain on injection of microemulsion propofol should be approximately $70 \%$ [8]. A reduction of $30 \%$ (from $70 \%$ to $40 \%$ ) in the treatment group would be considered clinically important. Therefore, 37 subjects per group would be needed to decrease this incidence to $5 \%$ (power $80 \%$ and $\alpha=0.05$ ). We assumed a dropout rate of $10 \%$ and so increased the sample size to 40 patients per group.

Statistical analyses were performed using SPSS software (version 16.0, SPSS Inc., IL, USA). Analyses of variance were performed on the demographic data, using the one-way ANOVA test and the chi-square test. The chi-square test was used to calculate differences between groups in incidence of microemulsion propofol-induced pain. Differences in the pain scores among the groups were analysed with the KruskalWallis rank test and Mann-Whitney tests were performed as

Table 2. Incidence and Severity of Pain on Propofol Injection

\begin{tabular}{lcccc}
\hline Severity of pain & $\begin{array}{c}\text { LS } \\
(\mathrm{n}=40)\end{array}$ & $\begin{array}{c}\text { LR 0.3 } \\
(\mathrm{n}=40)\end{array}$ & $\begin{array}{c}\text { LR 0.5 } \\
(\mathrm{n}=40)\end{array}$ & $\begin{array}{c}\text { LR } 1.0 \\
(\mathrm{n}=40)\end{array}$ \\
\hline 1 (No pain) & $14(35)$ & $25(62.5)^{*}$ & $35(87.5)^{*, \dagger}$ & $36(90)^{*, \dagger}$ \\
2 (Mild pain) & $18(45)$ & $15(37.5)^{*}$ & $5(12.5)^{*, \dagger}$ & $4(10)^{*,+}$ \\
3 (Moderate pain) & $8(20)$ & $0(0)^{*}$ & $0(0)^{*}$ & $0(0)^{*}$ \\
4 (Severe pain) & $0(0)$ & $0(0)$ & $0(0)$ & $0(0)$ \\
\hline
\end{tabular}

The values are shown as the number of patients (\%). LS: lidocaine 40 $\mathrm{mg}+$ saline $10 \mathrm{ml}$, LR 0.3: lidocaine $40 \mathrm{mg}+$ remifentanil $0.3 \mu \mathrm{g} / \mathrm{kgin}$ $10 \mathrm{ml}$, LR 0.5: lidocaine $40 \mathrm{mg}+$ remifentanil $0.5 \mu \mathrm{g} / \mathrm{kg}$ in $10 \mathrm{ml}, \mathrm{LR}$ 1.0: lidocaine $40 \mathrm{mg}+$ remifentanil $1.0 \mu \mathrm{g} / \mathrm{kg}$ in $10 \mathrm{ml}$. $* \mathrm{P}<0.05 \mathrm{com}-$ pared to the LS group, ${ }^{\dagger} \mathrm{P}<0.05$ compared to the LR 0.3 group. post-hoc test among the groups. $\mathrm{P}$ value $<0.05$ was considered significant. All values are expressed as mean (SD) or absolute numbers (\%).

\section{Results}

The overall incidence and intensity of pain during injection of microemulsion propofol in the groups is shown in Table 2. The incidence of pain from the microemulsion propofol injection in the LR 0.3, LR 0.5 and LR 1.0 groups (37.5\%, 12.5\%, and 10\%, respectively, $\mathrm{P}<0.05)$ was significantly lower than that in the LS group (65\%). The incidence of moderate pain disappeared completely in the LR 0.3 , LR 0.5 and LR 1.0 groups $(0 \%)$ compared with that in the LS group (20\%). The LR 0.5 and LR 1.0 groups showed significantly less frequent and intense pain than the LR 0.3. However, there was a similar incidence of injection pain in the LR 0.5 and LR 1.0 groups.

For all subjects, BIS score were above 90 before the microemulsion propofol injection, indicating adequate responses to questionnaires. The decrease in HR and MAP before intubation was statistically significant in all groups except HR in the LS group compared to the baseline value and in the LR 1.0 group compared to the LS group. However, the decrease of HR and MAP are of no clinical importance (Table 3). None of the patients suffered from desaturation or chest wall rigidity during the induction of anesthesia. There were no adverse effects observed at the injection site in any patient.

\section{Discussion}

Propofol-induced pain is a common problem and can be very distressing to the patient. It has been ranked by American anesthesiologists as the seventh most important drawback of

Table 3. Mean Arterial Pressure (MAP) and Heart Rate (HR)

\begin{tabular}{lllll}
\hline & $\begin{array}{c}\text { LS } \\
(\mathrm{n}=40)\end{array}$ & $\begin{array}{c}\text { LR 0.3 } \\
(\mathrm{n}=40)\end{array}$ & $\begin{array}{c}\text { LR 0.5 } \\
(\mathrm{n}=40)\end{array}$ & $\begin{array}{c}\text { LR 1.0 } \\
(\mathrm{n}=40)\end{array}$ \\
\hline MAP & & & & \\
$\quad$ Baseline & $96(14)$ & $99(15)$ & $102(13)$ & $97(14)$ \\
After remifentanil & $94(15)$ & $96(15)$ & $98(11)$ & $93(15)$ \\
$\quad$ Before intubation & $83(13)^{*}$ & $82(12)^{*}$ & $81(7)^{*}$ & $72(9)^{*,+}$ \\
HR & & & & \\
Baseline & $75(14)$ & $75(16)$ & $75(12)$ & $79(16)$ \\
After remifentanil & $75(13)$ & $76(18)$ & $74(13)$ & $75(15)$ \\
Before intubation & $71(10)$ & $66(11)^{*}$ & $66(10)^{*}$ & $63(8)^{*, \dagger}$ \\
\hline
\end{tabular}

Values are shown as mean (SD). Baseline: before intravenous injection of the saline or remifentanil, After Remifentanil: after the remifentanil or saline injection. LS: lidocaine $40 \mathrm{mg}+$ saline $10 \mathrm{ml}$, LR 0.3: lidocaine $40 \mathrm{mg}$ + remifentanil $0.3 \mu \mathrm{g} / \mathrm{kg}$ in $10 \mathrm{ml}$, LR 0.5: lidocaine $40 \mathrm{mg}+$ remifentanil $0.5 \mu \mathrm{g} / \mathrm{kg}$ in $10 \mathrm{ml}$, LR 1.0: lidocaine $40 \mathrm{mg}+$ remifentanil $1.0 \mu \mathrm{g} / \mathrm{kg}$ in $10 \mathrm{ml} .{ }^{*} \mathrm{P}<0.05$ compared to baseline, ${ }^{\dagger} \mathrm{P}<0.05$ compared to the LS group. 
current clinical anesthesiology [22].

Although the precise mechanism by which propofol induces pain at the time of injection has remained unclear, many factors that influence pain during propofol injection are known, including the speed of injection, speed of IV carrier fluid, and the buffering effect of blood [23,24]. Previous studies have shown that younger patients, patients with a peripheral IV site, female patients in general and female patients at the follicular phase of the menstrual cycle are more sensitive to pain on the injection of propofol $[25,26]$. In addition, it has been reported that the incidence and severity of pain during propofol injection was related to the formulation of propofol $[8,27]$.

In this study, there was a significantly lower incidence and intensity of microemulsion propofol injection pain in the combination group than in the LS group $(\mathrm{P}<0.05)$. The LR 0.5 and LR 1.0 groups showed significantly less frequent and intense pain than the LR 0.3 group $(\mathrm{P}<0.05)$. There was a similar incidence of injection pain in the LR 0.5 and LR 1.0 groups.

The most popular method for reducing injection pain is to mix lidocaine with propofol. This technique is easy, fast, does not affect the physiochemical property of the drug and more importantly is associated with a clinically and statistically significant reduction in the incidence and severity of pain $[13,23]$. The mechanism of the analgesic effect of lidocaine remains unclear, but is generally considered to be by the inhibition of the kinnin cascade $[23,28]$ or the dilutional effect on propofol [29].

Pretreatment with remifentanil has been reported to reduce the incidence and severity of pain during propofol injection $[15,16]$. Similar to other opioids, the action site of remifentanil may either be central or peripheral. Previous studies have shown that intravenous opioids given as Bier's block before propofol injection failed to show analgesic efficacy [30,31]. In this study, the patients received remifentanil and then 90 seconds later they received the microemulsion propofol injection. Thus, the mechanism of the analgesic effect of remifentanil may be related mainly to a central effect.

However, some patients do not respond well to lidocaine mixed with propofol and some patients continue to complain even with lidocaine administration. Moreover, the incidence of a painful injection of microemulsion propofol mixed with lidocaine $40 \mathrm{mg}$ in our study was $\sim 65 \%$. A previous study showed that remifentanil was effective in preventing propofol injection pain, and should be used at a dose of at least 0.02 $\mathrm{mg}$ for this purpose [15]. However, in a previous study, an intravenous remifentanil $0.5 \mu \mathrm{g} / \mathrm{kg}$ pretreatment was not effective in alleviating pain associated with a microemulsion propofol injection and the incidence of a painful injection was $90 \%[20]$. As a result, this incidence is unacceptable, which lead us to search for a new method. Recent studies show that combination therapy using different analgesic modalities can reduce the incidence and severity of propofol injection pain [17-19]. Also, recent studies revealed that a combination of opioids and lidocaine can reduce the incidence and severity of propofol injection pain compared to each drug used alone in adults $[17,32]$. In our study, the incidence of pain from the microemulsion propofol injection in the LR 0.3 , LR 0.5 and LR 1.0 groups (37.5\%, $12.5 \%$, and $10 \%$, respectively) was significantly lower than that in the LS group (65\%). A previous study show that the combination of pretreatment of remifentanil $(0.35 \mu \mathrm{g} / \mathrm{kg} / \mathrm{min})$ and a premixture of lidocaine with propofol (mixture of propofol $1 \%$ and lidocaine $1 \%$ in a $10: 1$ ratio) is more effective in reducing the incidence of pain on injection of propofol than either treatment alone [32]. Also, in this study, the combination of pretreatment of remifentanil and premixture of lidocaine with microemulsion propofol was more effective in a dose-dependent manner. The mechanism of action involved has not been identified, but it is possible that remifentanil enhances the analgesic efficacy of the lidocaine premixture. Further study elucidating the mechanism of this effect is therefore required.

Although, the decrease in HR and MAP before intubation was statistically significant in all groups except HR in the LS group compared to the baseline value, and in the LR 1.0 group compared to the LS group, the decrease of HR and MAP were of no clinical importance (Table 3). None of the patients suffered from desaturation, apnea and chest wall rigidity during the induction of anesthesia. For all subjects, BIS score were above 90, indicating adequate responses to questionnaires. There were no adverse effects at the injection site in any patient.

These findings should be considered within the context of the limitation of this study. First, we did not use higher doses of remifentanil. Higher doses of remifentanil would possibly produce further reductions in propofol injection pain. This will be of clinical benefit if it is not associated with an increase in the incidence of complications. Second, a non-treated control group was not included in this study. However, because microemulsion propofol produces more frequent and severe pain upon injection than lipid emulsion propofol, including a non-treated arm would not have been ethical.

In conclusion, a combination of pretreatment of remifentanil with premixture of lidocaine with microemulsion propofol was more effective in reducing the incidence of pain on injection of microemulsion propofol than just a premixture of lidocaine with microemulsion propofol alone. The combination of pretreatment of remifentanil $0.5 \mu \mathrm{g} / \mathrm{kg}$ and premixure of lidocaine $40 \mathrm{mg}$ had a similar analgesic effect compared to the combination of pretreatment of remifentanil $1.0 \mu \mathrm{g} / \mathrm{kg}$ and premixure of lidocaine. 


\section{References}

1. Bennett SN, McNeil MM, Bland LA, Arduino MJ, Villarino ME, Perrotta DM, et al. Postoperative infections traced to contamination of an intravenous anesthetic, propofol. N Engl J Med 1995; 333: 14754.

2. Park JW, Park ES, Chi SC, Kil HY, Lee KH. The effect of lidocaine on the globule size distribution of propofol emulsions. Anesth Analg 2003; 97: 769-71.

3. Devlin JW, Lau AK, Tanios MA. Propofol-associated hypertriglyceridemia and pancreatitis in the intensive care unit: an analysis of frequency and risk factors. Pharmacotherapy 2005; 25: 1348-52.

4. Yamakage M, Iwasaki S, Satoh J, Namiki A. Changes in concentrations of free propofol by modification of the solution. Anesth Analg 2005; 101: 385-8.

5. Baker MT, Naguib M. Propofol: the challenges of formulation. Anesthesiology 2005; 103: 860-76.

6. Kim KM, Choi BM, Park SW, Lee SH, Christensen LV, Zhou J, et al. Pharmacokinetics and pharmacodynamics of propofol microemulsion and lipid emulsion after an intravenous bolus and variable rate infusion. Anesthesiology 2007; 106: 924-34.

7. Jung JA, Choi BM, Cho SH, Choe SM, Ghim JL, Lee HM, et al. Effectiveness, safety, and pharmacokinetic and pharmacodynamic characteristics of microemulsion propofol in patients undergoing elective surgery under total intravenous anaesthesia. $\mathrm{Br} \mathrm{J}$ Anaesth 2010; 104: 563-76.

8. Sim JY, Lee SH, Park DY, Jung JA, Ki KH, Lee DH, et al. Pain on injection with microemulsion propofol. Br J Clin Pharmacol 2009; 67: 316-25.

9. Fragen RJ, de Grood PM, Robertson EN, Booij LH, Crul JF. Effects of premedication on diprivan induction. Br J Anaesth 1982; 54: 913-6.

10. McCrirrick A, Hunter S. Pain on injection of propofol: the effect of injectate temperature. Anaesthesia 1990; 45: 443-4.

11. Stokes DN, Robson N, Hutton P. Effect of diluting propofol on the incidence of pain on injection and venous sequelae. $\mathrm{Br} \mathrm{J}$ Anaesth 1989; 62: 202-3.

12. Saadawy I, Ertok E, Boker A. Painless injection of propofol: pretreatment with ketamine vs thiopental, meperidine, and lidocaine. Middle East J Anesthesiol 2007; 19: 631-44.

13. Gehan G, Karoubi P, Quinet F, Leroy A, Rathat C, Pourriat JL. Optimal dose of lignocaine for preventing pain on injection of propofol. Br J Anaesth 1991; 66: 324-6.

14. Ambesh SP, Dubey PK, Sinha PK. Ondansetron pretreatment to alleviate pain on propofol injection: a randomized, controlled, double-blinded study. Anesth Analg 1999; 89: 197-9.

15. Iyilikci L, Balkan BK, Gökel E, Günerli A, Ellidokuz H. The effects of alfentanil or remifentanil pretreatment on propofol injection pain. J Clin Anesth 2004; 16: 499-502.

16. Basaranoglu G, Erden V, Delatioglu H, Saitoglu L. Reduction of pain on injection of propofol using meperidine and remifentanil. Eur J Anaesthesiol 2005; 22: 890-2.
17. Aouad MT, Siddik-Sayyid SM, Al-Alami AA, Baraka AS. Multimodal analgesia to prevent propofol-induced pain: pretreatment with remifentanil and lidocaine versus remifentanil or lidocaine alone. Anesth Analg 2007; 104: 1540-4.

18. Kwak KH, Ha J, Kim Y, Jeon Y. Efficacy of combination intravenous lidocaine and dexamethasone on propofol injection pain: a randomized, double-blind, prospective study in adult Korean surgical patients. Clin Ther 2008; 30: 1113-9.

19. Fujii Y, Nakayama M. Prevention of pain due to injection of propofol with IV administration of lidocaine $40 \mathrm{mg}$ + metoclopramide 2.5, 5, or $10 \mathrm{mg}$ or saline: a randomized, double-blind study in Japanese adult surgical patients. Clin Ther 2007; 29: 856-61.

20. Han YK, Jeong CW, Lee HG. Pain reduction on injection of microemulsion propofol via combination of remifentanil and lidocaine. Korean J Anesthesiol 2010; 58: 435-9.

21. Hong SW, Kwak KH. The effects of different doses of remifentanil on propofol injection pain: a placebo controlled comparison of ketamine. Korean J Anesthesiol 2006; 51: 302-7.

22. Macario A, Weinger M, Truong P, Lee M. Which clinical anesthesia outcomes are both common and important to avoid? The perspective of a panel of expert anesthesiologists. Anesth Analg 1999; 88: 1085-91.

23. Scott RP, Saunders DA, Norman J. Propofol: clinical strategies for preventing the pain of injection. Anaesthesia 1988; 43: 492-4.

24. Klement W, Arndt JO. Pain on injection of propofol: effects of concentration and diluent. Br J Anaesth 1991; 67: 281-4.

25. Kang HJ, Kwon MY, Choi BM, Koo MS, Jang YJ, Lee MA. Clinical factors affecting the pain on injection of propofol. Korean J Anesthesiol 2010; 58: 239-43.

26. Hanci V, Ayoğlu H, Yilmaz M, Yurtlu S, Okyay RD, Erdoğan G, et al. Effect of menstrual cycle on the injection pain due to propofol. Eur J Anaesthesiol 2010; 27: 425-7.

27. Larsen B, Beerhalter U, Biedler A, Brandt A, Doege F, Brün K, et al. Less pain on injection by a new formulation of propofol? A comparison with propofol LCT. Anaesthesist 2001; 50: 842-5.

28. Iwama H, Nakane M, Ohmori S, Kaneko T, Kato M, Watanabe K, et al. Nafamostat mesilate, a kallikrein inhibitor, prevents pain on injection with propofol. Br J Anaesth 1998; 81: 963-4.

29. Eriksson M, Englesson S, Niklasson F, Hartvig P. Effect of lignocaine and $\mathrm{pH}$ on propofol-induced pain. Br J Anaesth 1997; 78: 502-6.

30. Wrench IJ, Girling KJ, Hobbs GJ. Alfentanil-mediated analgesia during propofol injection: no evidence for a peripheral action. Br J Anaesth 1996; 77: 162-4.

31. Pang WW, Mok MS, Huang S, Hwang MH. The analgesic effect of fentanyl, morphine, meperidine, and lidocaine in the peripheral veins: a comparative study. Anesth Analg 1998; 86: 382-6.

32. Kwak K, Kim J, Park S, Lim D, Kim S, Baek W, et al. Reduction of pain on injection of propofol: combination of pretreatment of remifentanil and premixture of lidocaine with propofol. Eur J Anaesthesiol 2007; 24: 746-50. 